\title{
26 Research Suare \\ Parasites and Parasitic Diseases of Laboratory Animals in Plateau State Nigeria: The Zoonotic Implications
}

\section{Olatunde B. Akanbi}

University of Ilorin Faculty of Veterinary Medicine

Shola David Ola-Fadunsin ( $\nabla$ olashodam2@yahoo.com )

University of Ilorin https://orcid.org/0000-0002-2265-2494

\section{Sadiq Yahaya}

University of Ilorin Faculty of Veterinary Medicine

Rebecca Kaye

University of Ilorin Faculty of Veterinary Medicine

\section{Rebecca Shamaki}

University of Ilorin Faculty of Veterinary Medicine

\section{Research Article}

Keywords: Laboratory animals, Nigeria, Parasites, Prevalence, Zoonosis

Posted Date: May 24th, 2021

DOl: https://doi.org/10.21203/rs.3.rs-537789/v1

License: (c) (i) This work is licensed under a Creative Commons Attribution 4.0 International License.

Read Full License

Version of Record: A version of this preprint was published at Journal of Parasitic Diseases on July 21st, 2021. See the published version at https://doi.org/10.1007/s12639-021-01420-y. 


\section{Abstract}

Parasitic infections in laboratory animals, are detrimental to the success of researches and can also infect personnel and researchers. This study is aimed at investigating the parasitic infections of laboratory animals maintained in animal houses of The National Veterinary Research Institute, Vom, Nigeria, as well determining the zoonotic implications of the parasites. Two hundred and six laboratory animals ( 55 guinea pigs, 72 rabbits, 29 rats and 50 mice) were sampled. Faecal samples and skin scrapings were collected and subjected to parasitological analyses. Pathological examinations were conducted on laboratory animals that had skin lesions. Sixteen different species comprising of 7 nematodes, 5 cestodes, 3 protozoans, and 1 mite were detected. Eimeria species $(40 / 206 ; 19.42 \% ; 95 \% \mathrm{Cl}$ $=14.44-25.25)$ was the most prevalent parasite, followed by Syphacia muris $(26 / 206 ; 12.62 \% ; 95 \% \mathrm{Cl}=$ 8.59 - 17.69). Entamoeba caviae, Tritrichomonas caviae, Rodentolepis microstoma, Rodentolepis nana, Heterakis spumosa, Capillaria hepatica and Cysticercus fasciolaris were the least prevalent with a $0.49 \%$ prevalence each. Three, four, five and six different species of parasites were detected in mice, guinea pigs, rats and rabbits respectively. The Chi square analysis revealed that the infection rate of parasites was significantly higher $(p=<0.01)$ in mice compared to guinea pigs, rabbits and rats. Of the Sixteen species of parasites detected, Eimeria species, Syphacia muris, Rodentolepis diminuta, Rodentolepis microstoma, Rodentolepis nana, and Capillaria hepatica are zoonotic. This study showed that $40.29 \%$ of the studied laboratory animals were infected with one parasite species or the other. The outcome of this study stresses the zoonotic implications of the parasites detected. We thereby advise researchers and handlers to take caution and apply utmost sanitary measures in the handling of laboratory animals so as to prevent themselves from been infected with these zoonotic parasites.

\section{Introduction}

Laboratory animals are animals used for biological studies in most academic and research institutions of the world. Laboratory animals includes but not limited to mice, rats, guinea pigs, rabbits, hamsters, and hare (Ademola and Ola-Fadunsin 2012). Laboratory animals have contributed significantly to the knowledge of biological structures and functions and are important tools in biological and medical researches, and training (Gudissa et al. 2011; Bassad et al. 2016). They are used for the diagnosis and studies of infective organisms, in the production of vaccines, sera and other biological substances of public health and veterinary importance, they are also used extensively in the safety evaluation of diverse therapeutic drugs, in comprehensive varieties of biological investigations and foods chemicals (Clark et al. 1997; Bassad et al. 2016).

There is need for living laboratory animals to be healthy and free from infections so as not to affect its purpose for been used for research (Bicalho et al. 2007; Tanideh et al. 2010). Laboratory animals can become heavily parasitized both externally and internally, with a variety of organisms ranging from parasites, viruses, fungi, bacteria, and mycoplasmas. Infection and infestations with these organisms lead to loss of time, money, loss of quality in the affected laboratory animals and research effort (Griffiths 1971; Ademola and Ola-Fadunsin 2012; Bassad et al. 2016; Dolatkhah et al. 2017). 
Parasites are of a great concern to the wellbeing and use of laboratory animals, among other infectious organisms. They become a prime target for parasitic infections if appropriate management and preventive measures are not practiced (Tanideh et al. 2010; Gudissa et al. 2011). Besides the high mortality caused by parasites in young animals, parasitic infections can also complicate research by inducing physiological, haematological, biochemical, pathological and immunological alterations in the hosts, exaggerating or diminishing host susceptibility to experimental stress, inducing tissue damages, stimulating abnormal growth of tissues, competing with the host for nutrients, decreasing the volume of host's blood and body fluids and by mechanical interference (Aboel-Hadid and Gamal 2007; Dolatkhah et al. 2017). A good number of parasites that affects laboratory animals are zoonotic in nature, and these include Aspicularia tetraptera, Eimeria species, Encephalitozoon cuniculi, Giardia species, Hymenolepis (now Rodentolepis) nanac, R. diminuta, Physaloptera species, Polyplax species, Schistosoma species, Syphacia muris, S. obvelata, Taenia species, Trichomonas species, lice, and mites, etc. (Huq et al. 1985; Tanideh et al. 2010; Taylor et al. 2016; Dolatkhah et al. 2017).

In view of the considerable adverse effects of parasitic infections on the health status and research abilities of laboratory animals, and the possible transmission of zoonotic parasites infections between laboratory animals and personnel or researchers, this study is therefore aimed to investigate the parasitic infections of laboratory animals maintained conventionally in the small animal houses of the National Veterinary Research Institute, Vom, Plateau State Nigeria, as well determining the zoonotic implications of the parasites.

\section{Materials And Methods}

\section{Study location}

This study was conducted in the laboratory animal houses of the National Veterinary Research Institute, Vom, Plateau State Nigeria. The National Veterinary Research Institute, Vom is the central diagnostic and research center for animal diseases, their treatment and control in Nigeria. They are responsible for the production of animal vaccines, sera and biological to meet national demands. They are also responsible for training intermediate manpower in Veterinary laboratory technology and animal health and production technology, as well as providing extension services to poultry and livestock farmers. The surveillance and diagnosis of animal diseases and the introduction of exotic stock for improved egg, meat and milk production is also been shouldered by this institute (NVRI 2021). The National Veterinary Research Institute, is located in Plateau State. Plateau State covers a land mass of 27,147 square kilometers and is one of the largest states in Nigeria and is almost centrally located between latitude $80^{\circ} 24$ ' $\mathrm{N}$, and longitude $80^{\circ} 32^{\prime}$ and $100^{\circ} 38^{\prime}$ east of the Greenwich meridian. The state has a high altitude ranging from approximately 1,200 to a peak of 1,829 meters above sea level. Plateau State has an almost temperate climate with a mean annual rainfall of between $131.75 \mathrm{~cm}$ to $146 \mathrm{~cm}$ and a mean annual temperature of $16.3^{\circ} \mathrm{C}$ to $28.1^{\circ} \mathrm{C}$. It records an average relative humidity of between $46.9 \%$ and $51.3 \%$ (Bolajoko et al. 2016; Karaye et al. 2018). 


\section{Study animals}

A total of 206 laboratory animals comprising of 55 guinea pigs, 72 rabbits, 29 rats and 50 mice were used for this study. The laboratory animals were collected from the different laboratory animal houses in the institute.

\section{Collection of samples}

Freshly passed faecal samples were collected from each laboratory animal into clean and sterile sample bottles. Each laboratory animal was carefully and thoroughly examined for the presence of ectoparasite(s) with skin scrapping taken as the case may be. The collected samples were immediately transported to the parasitology and or pathology units of the Central diagnostic laboratory of the National Veterinary Research Institute, Vom, Plateau State, for further parasitological and pathological analyses.

\section{Parasitological processing}

Faecal samples were analysed using the direct faecal smear and the simple flotation techniques. The direct faecal smear technique was carried out as described by Soulsby (1982). Briefly, faeces was emulsified in 1 or 2 drops of normal saline on a clean glass microscopic slide with an applicator. Afterwards a drop of iodine was added to the mixture, then a coverslip was carefully placed over the suspension, ensuring that it is thin, uniform and clear. It was then examined under the microscope using $\mathrm{X} 10$ or X40 objective of the microscope. The simple flotation technique was carried out as described by Taylor et al. (2016). Briefly, faecal samples were placed in universal bottles and mixed with little quantity of saturated sodium chloride $(\mathrm{NaCl})$ solution. This mixture was then sieved into a test tube. Afterward, the filtrate was filled to the brim (forming a meniscus) with more of the saturated $\mathrm{NaCl}$ solution and a clean cover slip was gently placed on top of the test tube whereby avoiding spillage. The cover slip was left for about 20 minutes; afterwards, the cover slip (having the harvested eggs) was placed on a clean glass slide for microscopic examination, using X10 or X40 objective of the microscope.

Skin scrapings were analysed by dissolving it in $10 \% \mathrm{KOH}$, then it was viewed using the $\mathrm{X} 10$ or $\mathrm{X} 40$ objective of the microscope. Parasitological keys by Kassai (1999), Charles and Hendrix (2006), and Zajac and Conboy (2012) were used in the identification of the helminths, protozoans and mites obtained in this study.

\section{Gross and histopathological examination}

Rats that showed skin lesions were humanely euthanized according to the guidelines of the Animal Welfare and Ethics Committee of the National Veterinary Research Institute (NVRI), Vom, Nigeria. Skin, liver, and intestines with gross lesions were fixed in buffered formalin. Tissue cuts of $0.5 \times 0.5 \mathrm{~cm}$ in diameter from the tissues were made with scalpel blade, after which they were placed in automatic tissue processor for processing, dehydrated in ethanol (70-100\%), cleared in xylene, and embedded in paraffin at the Central Diagnostic laboratory, NVRI Vom. Five (5) - $\mu \mathrm{m}$ paraffin-wax sections of organs were dewaxed and stained with hematoxylin-eosin (H\&E), mounted on charged microscope slides, and observed under a 
Carl Zeiss light microscope for histopathological changes as previously described by Kamani et al. (2013) or under a low and high-powered field of Carl Zeiss ${ }^{\circledR}$ Axio Imager A1 binocular microscope and IC3 mounted camera was used for photographing the microscopic lesion as described by Akanbi (2020).

\section{Statistical analysis}

Data were initially entered in Microsoft office Excel version 2019 for the determination of percentages (\%) with their corresponding 95\% confidence intervals. Chi-square $\left(\chi^{2}\right)$ test for discrete variables at $95 \%$ confidence interval was used to determine the associations between each of the laboratory animal species in relations to parasitic infections. Statistical significance was set at $p<0.05$.

\section{Results}

Off the 206 laboratory animals sampled, 83 were infected with one parasite or the other (Fig. 1), representing $40.29 \%$ of the sampled population with a $95 \% \mathrm{Cl}$ of $33.75-47.10$. In total, 16 parasites consisting of nematodes (7), cestodes (5), protozoans (3) and mites (1) were detected (Fig. 2). Eimeria species $(40 / 206 ; 19.42 \% ; 95 \% \mathrm{Cl}=14.44-25.25)$ was the most prevalent parasite species followed by Syphacia muris $(26 / 206 ; 12.62 \% ; 95 \% \mathrm{Cl}=8.59-17.69)$. Entamoeba caviae, Tritrichomonas caviae, Rodentolepis microstoma, Rodentolepis nana, Heterakis spumosa, Capillaria hepatica and Cysticercus fasciolaris were the least in occurrence with a $0.49 \%$ prevalence each (Fig. 2). Eimeria species and Trichostrongylus retortaeformis were the only parasites detected in two of the four laboratory animals studied.

In guinea pigs, 4 parasites were detected, with Eimeria species $(32.73 \% ; 95 \% \mathrm{Cl}=21.34-45.89)$ been the most prevalent, while Entamoeba caviae and Tritrichomonas caviae were the least prevalent with (1.81\%; $95 \% \mathrm{Cl}=0.09-8.64$ ) each (Table 1). Six different parasites species were detected in rabbits, with Eimeria species been the most prevalent (30.55\%), while others recorded a prevalence of (2.78\%) each (Table 2). All the five parasites detected in rats had a single occurrence with a prevalence of $3.45 \%(95 \% \mathrm{Cl}=0.17-$ 15.85) (Table 3). Syphacia muris $(26 / 50 ; 52.00 \%)$ was the most prevalent parasite amongst mice followed by Aspicularis tetraptera $(6 / 50 ; 12.00 \%)$, with Rodentolepis diminuta $(5 / 50 ; 10.00 \%)$ been the least prevalent (Table 4). The Chi square analysis showed that the infection rate of parasites was significantly higher $(p=<0.01)$ in mice $(68.00 \%)$ compared to rats $(10.34 \%)$, rabbits $(36.11 \%)$ and guinea pigs $(36.36 \%)$ (Table 5$)$. 
Table 1

Prevalence of parasites infecting guinea pigs in Plateau State, Nigeria $(n=$ $55)$.

\begin{tabular}{|llll|}
\hline Parasites & N & Prevalence (\%) & $\mathbf{9 5 \%} \mathbf{C l}$ \\
\hline Eimeria species & 18 & 32.73 & $21.34-45.89$ \\
\hline Trichostrongylus retortaeformis & 3 & 5.45 & $1.41-14.13$ \\
\hline Entamoeba caviae & 1 & 1.81 & $0.09-8.64$ \\
\hline Tritrichomonas caviae & 1 & 1.81 & $0.09-8.64$ \\
\hline
\end{tabular}

$\mathrm{N}=$ number of laboratory animals infected, $\mathrm{Cl}=$ Confidence interval

Table 2

Prevalence of parasites affecting rabbits in Plateau State, Nigeria $(n=72)$.

\begin{tabular}{|llll|}
\hline Parasites & N & Prevalence (\%) & $95 \% \mathrm{Cl}$ \\
\hline Eimeria species & 22 & 30.55 & $20.76-41.89$ \\
\hline Trichostrongylus retortaeformis & 2 & 2.78 & $0.47-8.88$ \\
\hline Cittotaenia ctenoides & 2 & 2.78 & $0.47-8.88$ \\
\hline Passalurus ambiguus & 2 & 2.78 & $0.47-8.88$ \\
\hline Graphidium strigosum & 2 & 2.78 & $0.47-8.88$ \\
\hline Psoroptes cuniculi & 2 & 2.78 & $0.47-8.88$ \\
\hline
\end{tabular}

$\mathrm{N}=$ number of laboratory animals infected, $\mathrm{Cl}=$ Confidence interval

Table 3

Prevalence of parasites infecting rats in Plateau State, Nigeria $(n=$ 29).

\begin{tabular}{|llll|}
\hline Parasites & $\mathbf{N}$ & Prevalence (\%) & $\mathbf{9 5 \%} \mathbf{C l}$ \\
\hline Rodentolepis microstoma & 1 & 3.45 & $0.17-15.85$ \\
\hline Rodentolepis nana & 1 & 3.45 & $0.17-15.85$ \\
\hline Heterakis spumosa & 1 & 3.45 & $0.17-15.85$ \\
\hline Capillaria hepatica & 1 & 3.45 & $0.17-15.85$ \\
\hline Cysticercus fasciolaris & 1 & 3.45 & $0.17-15.85$ \\
\hline
\end{tabular}

$\mathrm{N}=$ number of laboratory animals infected, $\mathrm{Cl}=$ Confidence interval 
Table 4

Prevalence of parasites infecting mice in Plateau State, Nigeria ( $\mathrm{n}$ $=50)$.

\begin{tabular}{|llll|}
\hline Parasites & N & Prevalence (\%) & $95 \%$ Cl \\
\hline Syphacia muris & 26 & 52.00 & $38.24-65.54$ \\
\hline Rodentolepis diminuta & 5 & 10.00 & $3.76-20.78$ \\
\hline Aspicularis tetraptera & 6 & 12.00 & $5.01-23.29$ \\
\hline
\end{tabular}

$\mathrm{N}=$ number of laboratory animals infected, $\mathrm{Cl}=$ Confidence interval

Table 5

Chi Square analysis on parasites infection rate of different laboratory animals in Plateau State, Nigeria.

\begin{tabular}{|llllll|}
\hline Laboratory animals & $\mathbf{n}$ & Number positive (\%) & $\chi^{2}$ & DF & p-value \\
Guinea pigs & 55 & $20(36.36)$ & 27.64 & 3 & $<0.01$ \\
Rabbits & 72 & $26(36.11)$ & & & \\
\cline { 1 - 5 } Rats & 29 & $3(10.34)$ & & & \\
Mice & 50 & $34(68.00)$ & & & \\
\hline
\end{tabular}

$\mathrm{n}=$ Number of laboratory animals sampled DF = Degrees of Freedom.

Grossly, rough skin coat, presence of parasitic vacuole and rough intestinal mucosa were seen in two rats. Microscopic examination of skin, liver, and intestines revealed histopathological lesions. Within the liver, there was a single parasitic vacuole (cyst) on the right middle lobe (Fig. 3a). The liver section showed the presence of a parasitic cestode larvae in a cyst consistent with Cysticercus fasciolaris without any tissue reaction around the cyst (Fig. 3b). In another rat, the liver section contained several multifocal parasitic vacuoles with numerous Capillaria hepatica and two other vacuoles with unhatched cysts of Cysticercus fasciolaris (Fig. 3c), with severe diffuse chronic hepatitis and infiltration by mononuclear cells. Within the subcutaneous muscles, was a single parasite in the muscle of Capillaria hepatica infected rat (Fig. 3d).

\section{Discussion}

Off the Sixteen parasites species detected, Eimeria species, Syphacia muris, Rodentolepis diminuta (formerly Hymenolepis diminuta), Rodentolepis microstoma (formerly Hymenolepis microstoma), Rodentolepis nana (formerly Hymenolepis nana) and Capillaria hepatica are zoonotic (Tanideh et al. 2010; Taylor et al. 2016; Dolatkhah et al. 2017), hereby stressing the need for researchers and handlers to take caution and apply utmost sanitary measures to prevent themselves from been infected.

The total prevalence of $40.29 \%$ we observed is lower than the $56.48 \%$ observed among laboratory animals in Ibadan, Nigeria (Ademola and Ola-Fadunsin 2012) and the 66.0\% reported in Nasiriyah, Iraq 
(Bassad et al. 2016). Our reported prevalence is higher than the prevalence (37.62\%) documented among laboratory animals in Addis Ababa, Ethiopia (Gudissa et al. 2011). These reports suggest that parasitic infections among laboratory animals is of cosmopolitan concern.

We reported Sixteen different species affecting laboratory animals in the study area. This number is higher than the five different species reported by Najafi et al. (2014) in Tehran, Iran, and the six reported by Tanideh et al. (2010) in Shiraz, Iran. Despite the fact that we detected a higher number than those documented in studies done in Iran, ours was lower than the seventeen different species reported among laboratory animals in Brazil (Gilioli et al. 2000). The disparity in the number of parasites affecting laboratory animals in these studies may be attributed to managemental, environmental and climatic factors. Eimeria species was the most prevalent parasite in this study. It was also the most prevalent parasite among guinea pigs and rabbits. Similarly, noticeable prevalence of Eimeria species has been reported among laboratory animals in Nigeria and other parts of the world (Gilioli et al. 2000; Gudissa et al. 2011; Ademola and Ola-Fadunsin 2012). This is not surprising as Eimeria species is believed to be ubiquitous in its distribution, been present wherever animals are raised (Ola-Fadunsin and Ademola 2013).

Syphacia muris was the most prevalent parasite found in mice. Syphacia species are known to infect mice and rats, and it has been documented to be the most prevalent helminth among mice and rats in previous studies (Gilioli et al. 2000; Aboel-Hadid and Gamal 2007; Tanideh et al. 2010). The high prevalence of Syphacia muris recorded among mice may be attributed to the fecundity of the parasite. Syphacia muris is a pin worm, and a gravid female can lay up to 50,000 eggs (Taylor et al. 2016).

Mice were most affected with parasites compared to guinea pigs, rabbits and rats. This observation is in tandem with reports by Gudissa et al. (2011) and Najafi et al. (2014) who documented higher prevalence of parasitism in mice compared to rats. Although, Hayunga (1991) documented a contrary report to our findings. The high prevalence of parasitism we recorded in mice may be attributed to the stocking density and husbandry practices of mice.

\section{Conclusion}

About $41.00 \%$ of the sampled laboratory animals were infected with one parasite or the other. Sixteen different species of parasites were detected among the sampled laboratory animals, and these parasites cuts across been nematodes, cestodes, protozoans and mites, with nematodes been be most predominant. Mice were most infected with parasites compared to guinea pigs, rabbits and rats. Of the sixteen parasites detected, six (Eimeria species, Syphacia muris, Rodentolepis diminuta, Rodentolepis microstoma, Rodentolepis nana and Capillaria hepatica) are zoonotic. This outcome stresses the zoonotic implications of the parasites detected in our study. We thereby advise researchers and handlers to take caution and apply utmost sanitary measures in the handling of laboratory animals so as to prevent themselves from been infected with these zoonotic parasites. 


\section{Declarations}

\section{Acknowledgement}

We grateful to Mrs. Victoria Olabode and Mr. Mada Alesa of the Central Diagnostic Laboratory of the National Veterinary Research Institute for their technical assistance.

\section{Conflicts of Interest Statement}

The authors declare that they have no conflicts of interest.

\section{Ethical approval}

This study was approved by the Animal Welfare and Ethics Committee of the National Veterinary Research Institute (NVRI), Vom, Nigeria. All applicable international, national, and/or institutional guidelines for the collection of faecal samples and skin scrapings from laboratory animals were appropriately followed.

\section{References}

1. Aboel-Hadid SM, Gamal AA (2007) Investigation of helminth parasitic infection of laboratory animals (rats \& mice) with special reference to control of Hymenolepis nana as a zoonotic parasite. Egypt $J$ Exp Biol (Zool) 3:83-89.

2. Ademola IO, Ola-Fadunsin SD (2012) Prevalence of gastrointestinal parasites of laboratory animals in Ibadan, Nigeria. Trop Vet 30(1):32-38.

3. Akanbi OB (2000) Spontaneous Zymbal's gland carcinoma with splenic and lymph node metastasis in Wistar rat. $63^{\text {rd }}$ conference der Fachgruppe Pathologie der Deutschen Veterinärmedizinischen Gesellschaft, 2000 July, Tierärztliche Praxis. Ausgabe K, Kleintiere/Heimtiere 48(3).

4. Bassad AA, Rabab AA, Alyaa AH (2016) Detection of intestinal parasites in laboratory animals (rats and mice). Eur J Biomed Pharm Sci 3(6):07-09.

5. Bicalho KA, Araujo FTM, Rocha RS, Carvalho OS (2007) Sanitary profile in mice and rats colonies in laboratory animal houses in Minas Gerais: Endo and Ectoparasite. Rq Bras Med Vet Zootec 59:1478-148. 10.1590/S0102-09352007000600020

6. Bolajoko M, Ahmed MS, Okewole PA, Kumbish P, Muhammad M, Fyfe J (2016) Prevalence and Demographic Distribution of Canine Rabies In Plateau State, Nigeria, 2004 - 2009. Bull Anim Health Prod Afr 64(1):127-136.

7. Charles M, Hendrix (2006) Diagnostic parasitology for veterinary technicians. 3rd ed. Elsevier Mosby, Edinburgh.

8. Clark HE, Coat MEJK, Ford DJ, Miliner CK, Odorogue PN, Scott PP, Ward RJ (1997) Dietary standards for laboratory Animals: Report of Laboratory Animals Centre Diets Advisory Committee. Lab Anim Rep 11:1-4. 
9. Dolatkhah A, Nematollahi A, Shahbazi P, Mesghari M (2017) Prevalence of parasitic infections of mice and rats in research centers of Tabriz universities. J Zoonotic Dis 2(2):37-44.

10. Gilioli R, Andrade LAG, Passos LAC, Silva FA, Rodrigues DM, Guaraldo AMA (2000) Parasite survey in mouse and rat colonies of Brazilian laboratory animal houses kept under differents sanitary barrier conditions. Arquivo Brasileiro de Medicina Veterinária e Zootecnia 52:33-37.

11. Griffiths HJ (1971) Some common parasites of small laboratory animals. Lab Anim 5:123-135.

12. Gudissa T, Mazengia H, Alemu S, Nigussie H (2011) Prevalence of gastrointestinal parasites of laboratory animals at Ethiopian Health and Nutrition Research Institute (EHNRI), Addis Ababa. J Infect Dis Immun 3(1):1-5.

13. Hayunga EG (1991) Morphological adaptations of intestinal helminths, J Parasitol 77:865-873.

14. Huq MM, Karim MJ, Sheikh H (1985) Helminth Parasites of rats, house mouse and moles in Bangladesh. Pak Vet J 5:143-144.

15. Kamani J, Akanbi BO, Baneth G, Morrick D, Harrus S (2013) Co-infection with Capillaria hepatica and Bartonella elizabethae in a Brown Rat (Rattus norvegicus) from Nigeria. Isr J Vet Med 68(4):230233.

16. Karaye PG, Ola-Fadunsin SD, Dogo GA (2018) Diversity of gastrointestinal parasites affecting some animals in Plateau State, North Central Nigeria. Sci World J 13(1):82-86.

17. Kassai T (1999) Veterinary Helminthology. 1st ed. Butterworth-Heinemann, Oxford.

18. Najafi F, Rezaie S, Kia E, Mobedi I, Mahmoudi M, Salimi M, Hasanpour H, Makki M, Mowlavi G (2014) Intestinal Helminths in Laboratory Mice and Rats in Four Research Centers, Tehran, Iran. J Med Microbiol Infect Dis 2(4):130-132.

19. National Veterinary Research Institute (NVRI) (2021) The mandate of the National Veterinary Institute. Available at: https://nvri.gov.ng/about. Accessed 14 May 2021.

20. Ola-Fadunsin SD, Ademola IO (2013) Direct effects of Moringa oleifera acetone extracts on broiler chickens naturally infected with Eimeria species. Trop Anim Health Prod 45(3):1423-1428.

21. Soulsby E JL (1982) Helminths, Arthropods and Protozoa of Domestic Animals. 7th ed. Beilliere Tindall, London, Philadelphia and Toronto.

22. Tanideh N, Sadjjadi SM, Mohammadzadeh T, Mehrabani D (2010) Helminthic Infections of Laboratory Animals in Animal House of Shiraz University of Medical Sciences and the Potential Risks of Zoonotic Infections for Researchers. Iran Red Crescent Med J 12(2):151-157.

23. Taylor MA, Coop RL, Wall RL (2016) Veterinary Parasitology. 4th ed. John Wiley and Sons, Ltd., The Atrium, Southern Gate, Chichester, West Sussex, United Kingdom.

24. Zajac AM, Conboy GA (2012) Veterinary Clinical Parasitology. 8th ed. John Wiley and Sons, Ltd., The Atrium, Southern Gate, Chichester, West Sussex, United Kingdom.

\section{Figures}



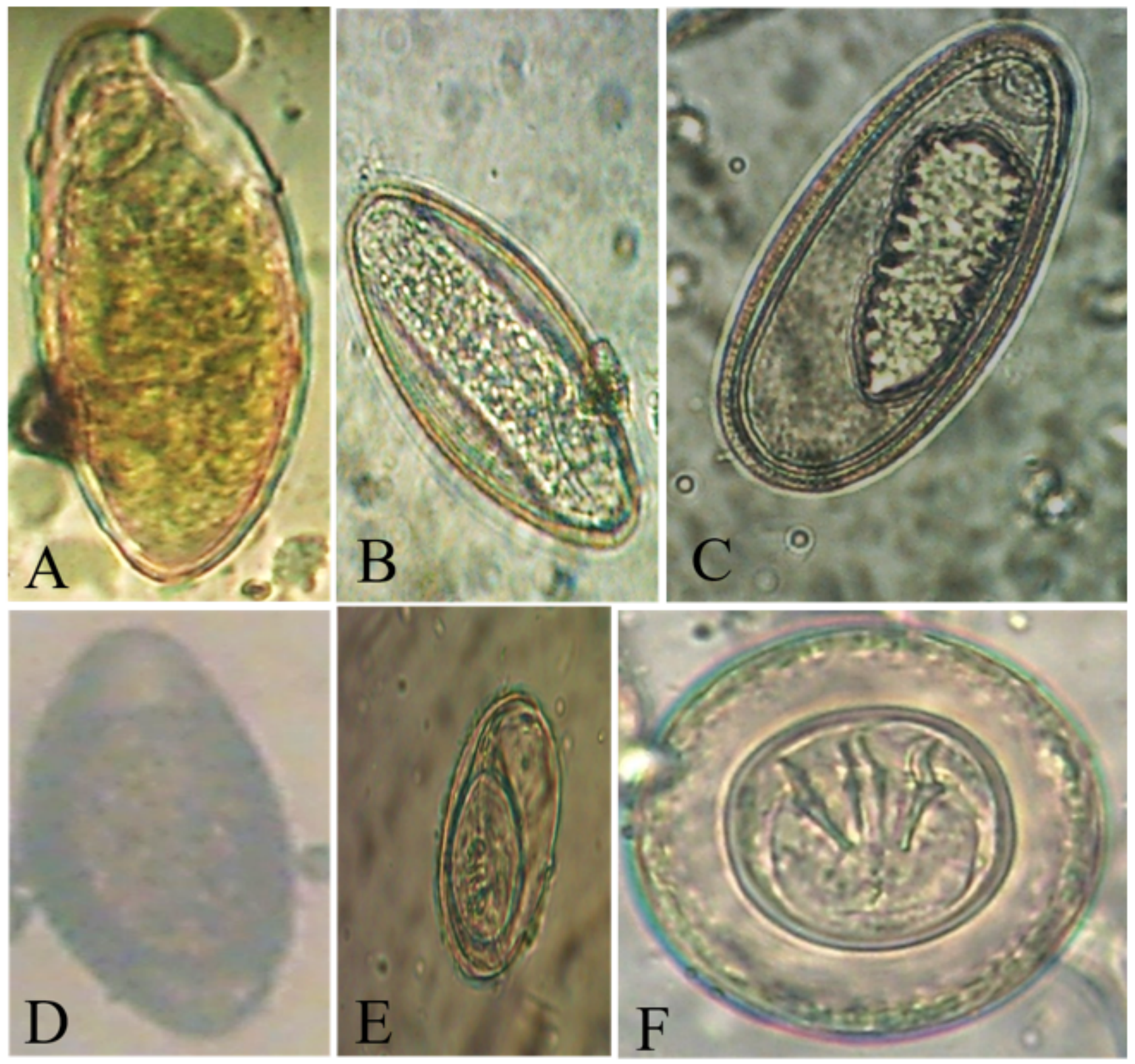

\section{Figure 1}

Some parasites found in laboratory animals in Plateau State, Nigeria. $A=$ Trichostrongylus retortaeformis; $B=$ Syphacia muris; $C=$ Graphidium strigosum; $D=$ Aspicularis tetraptera; $E=$ Passalurus ambiguus and $\mathrm{F}=$ Rodentolepis diminuta (X400 magnification). 


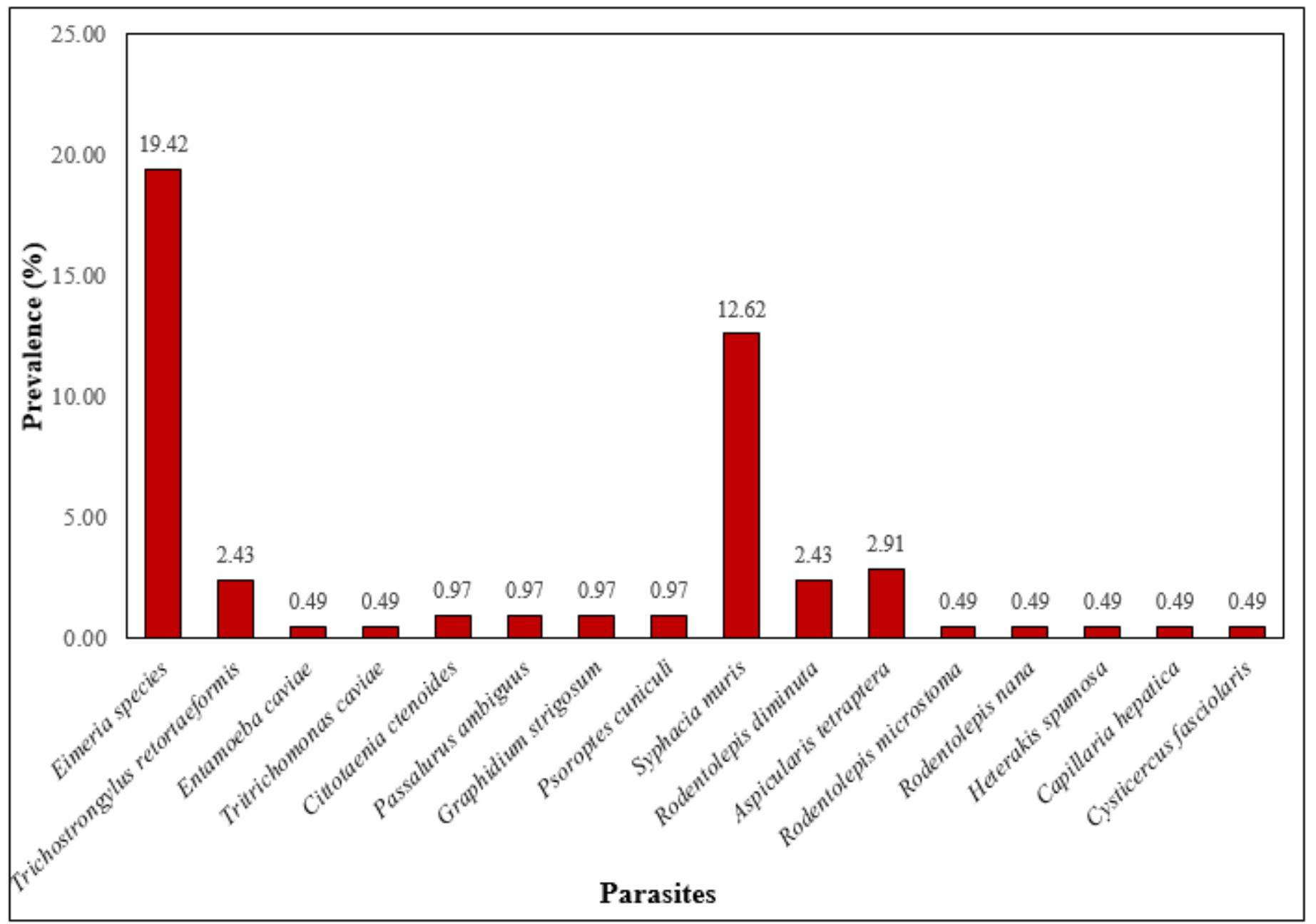

Figure 2

Overall prevalence of parasites affecting laboratory animals (guinea pigs, rabbits, and mice) in Plateau State, Nigeria $(n=206)$. 

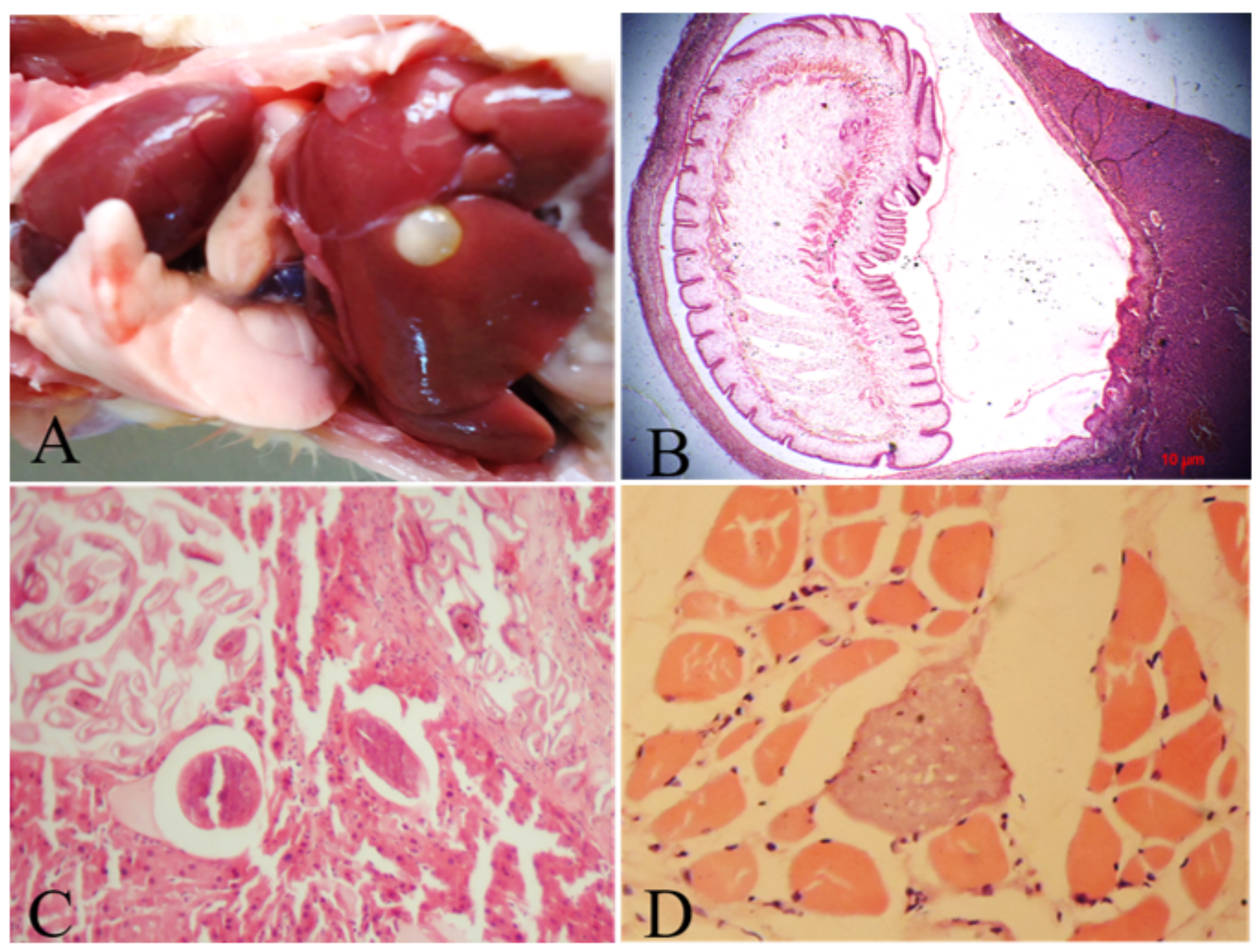

Figure 3

Gross and histopathology of parasites in rats; 3a, the liver has a single parasitic vacuole (cyst of (Cysticercus fasciolaris) on the right middle lobe. $3 \mathrm{~b}$, the liver section showed the presence of a parasitic cestode larvae in a cyst consistent with Cysticercus fasciolaris. 3c, the liver section contained several multifocal parasitic vacuoles with numerous Capillaria hepatica and two other vacuoles with unhatched cysts. $3 \mathrm{~d}$, the subcutaneous muscles contained a single parasite in the muscle identified as Rodentolepis microstoma same rat as $3 \mathrm{c}$. 